monia was discovered in the right lung. The autopsy confirmed the diagnosis and showed simple fractures of several ribs. ${ }^{1}$

CASE ti.-Foss's second case is somewhat similar to his first. There is a slight lacerated wound of the seapula without fracture, but which penetrated to the bone. Almost immediately the diagnosis of pneumonia was made and was confirmed by the autopsy four days later."

CASE 7.-Sturges reported a case in a sailor, aged 30 , who fell into the mud and sustaned a slight injury. Pneumonia developed almost immediately, and death resulted in six days. ${ }^{5}$

('Ase 8.-The second case reported by sturges is a simple contusion pneumonia. A stone mason was struck on the chest by a heavy marble slab and knocked down by the severe blow. Xo ribs were fractured, but in a few days a typical apex preumonia developed. ${ }^{\circ}$

In the last four cases mentioned the question arises whether the jeneumonia may not have existed before the triama occurrel. It is well known that sometimes those sufferine from febrile affections walk around for several dilys after the onset of the initial symptoms. This is especially true of typhoid fever patients and particularly $\therefore$ in the case of children. It is rare, however, for those wffering from pneumonia to go about, because usually the prostration is so great as to cause them to remain in bed from the very onset.

\section{INJURIES OF THE SPINAL CORD,}

WITII THE STCDY OF NINE CASES WI'TI NECROPSY.*

ALFRED REGINALD ALLEN, M.D.

Instructor in Neurology and in Neuro-Pathology in the University of Pennsylvania; Assistant Neurologist to the Philadelphia General IIospital. PHILADELPHIA.

It is my purpose to deal with injuries of the spinal cord secondary to external violence, such as gunshot wounds, fracture-dislocation of the spinal column with involvement of the cord, and involvement of the cord in spinal concussion without spinal lesion. At this time I shall not discuss injuries of the cord from stab wounds.

There are a few points concerning the anatomy of the spinal column to which I wish to call attention before discussing any cases of fracture-dislocation. From our standpoint, the spinal column consists of twenty-four true vertcbre. The sacrum, which is morphologically five vertebra, we consider in the light of a sing'e bone. of the coccyx I shall say very little, as it is interesting, clicfly, on account of a possibly faulty ankylosis in cases of fracture or contusion. The ligaments of the sp nal column, next to the bony conformation of the vertebræ themselves, play the largest part in the prevention of displacement. The following ligaments are those concerned in the binding together of the integral parts of the spinal column: the intervertebral discs, the anterior common ligament, the posterior common ligament, the interspinous ligaments, tle supraspinous ligaments, the intertransrerse ligaments. the capsular ligaments and the ligamenti subflarie. The last named are composed, chicfly, of yellow elestic tissue, and serve, rather, to close in the vertebral canal, than to give protection from injury or prevent overflexion.

4. Brit. Med. Jour., 1884, vol. 1. p. 1042

5. London Lancet, April 24, 1886 .

6. Lrit. Med. Jour.. March 1, 1879 .

* Read in the Section on Nervous and Mental Diseases of the * Read in the Section on Nervous and Mental Diseases of the is here abbreviated, but appears in full in the Transactions of the Section and in the author's reprints.

* From the Department of Neurology and the Laboratory of Neuro-Pathology in the Univer'sity of Pennsylvania.
The articulation between a superior articular process and its contiguous inferior process is a true diarthrosis of the arthrodial type. On examining a ligamentous preparation of the spinal column, one is struck with the fact that there is very little movement between any two vertebræ, with the single exception of the atlas on the axis. Taken as a whole, however, there is a very great latitude of movement. This is most conspicuous in the cervical region where extension is possible to a surprising extent; likewise flexion, to some extent. In the lumbar region flexion is chiefly predominant. In the thoracic region, on account of the thinness of the intervertebral discs, as also on account of the tile-like arrangement of the lamine through the middle part of the thoracic spine, there is very little motion. At the two ends of the thoracic spine, however, this tile-like arrangement of the lamine and the obliquity of the spinous processes are much less, and motion is consequently greater in these regions. Another condition which limits motion in this region is the articulation of the thorax and the very heavy binding which the heads and tubercles of the various ribs possess in their stellate ligaments. According to Wagner and Stolper, the greatest capability of extension and flexion of the spinal column is in the cervical region, from the third to the seventh vertebra, and also from the eleventh thoracic to the second lumbar vertebra.

A vertebral dislocation presupposes, in the first place. a greater or less disturbance of the integrity of the intervertebral discs between bodies of the two vertebræ in question. One finds numerous cases cited in literature where on postmortem examination the intervertebral disc has been pronounced uninjured. I consider this an absolute impossibility. $\Lambda$ more careful histologic study would have determined a torn dise.

Fractures and dislocatons in the thoracic region, above the tenth thoracic vertebra, are not so frequent as those in the cervical region or as those below the tenth thoracic vertebra. Also, it can be said that fracture and dislocation more frequentlv involve the lumbar vertebræ than the junction between the twelfth thoracic and the first lumbar. More than half of all the fractures of the spinal column are. according to Penres Bailey, located below the tenth thoracic vertebra. This statement is hardly borne out by statistics.

Burrell, ${ }^{2}$ in a collection of 244 cases of fracture-dislocation, gives 86 in the cervical region, 43 in the upper thoracic, 75 in the lower thoracic, and 40 in the lumbar. When thoracic fracture-dislocation takes place, it is on account of terrific violence, deformity is usually pronounced, and the cord much injured; but, as will be seen further in this discussion, there must be fracture in this region to produce a crushing of the cord, the possibility of a thoracic dislocation without fracture having been denied by Treves. ${ }^{3}$

The articular processes of the cervical vertebræ are set well out from the body. to such an extent, in fact, that any force which would tend to push a vertebra forward, providing it were great enough to overcome the ligamentous protection common to all vertebræ, would not find the bony obstruction which lower down the anterior aspect of the inferior intervertebral notch offers to the posterior aspect of the superior interverte-

1. Diseases of the Nervous System Resulting from Accident and Injury, D. Appleton \& Co., 1906.

2. A Summary of All the Cases of Fracture of the Spine (244) which were Treated at the Boston City Hospital from 1864 tc 1905, Trans. Am. Surg. Assn., vol. xxiii, 1905, p. 56.

3. Surgical Applied Anatomy, 1894, p. 546. 
bral notch of the vertebra immediately below it. In fact, the articular surfaces are so far separated in the cervical region that with very little longitudinal separation a complete luxation backward can obtain, the body of the upper vertebra resting on the spinal foramen of the vertebra below. As a matter of fact, however, this luxation is rarely seen, the opposite being usually the case; that is to say, the upper or luxated vertebra passes forward. To my mind, there are several reasons for this. The first is that usually the direction of force which brings about the fracture-dislocation is such that the spine is flexed instead of extended, and in a flexion the line of least resistance is certainly forward, on account of the fact that the anterior superior lip of the vertebral body is rounded off and inclines downward in the cervical region, while in the thoracic region the bodies of the vertebræ are a trifle thicker posteriorly than anteriorly. This inclination forward and downward, invites a slipping forward of the luxated vertebra, which carries with it the intervertebral disc attached to its inferior surface. This intervertebral disc, in the vast majority of cases, succeeds in tearing away the anterior superior lip of the body of the vertebra next below. The obliquity of a fracture of this nature, that is to say, from above posteriorly, in a direction down and anterior, makes a sliding displacement of the upper fragment very easy, and the deformity is often great. It is this deformity which most frequently nips the spinal cord in two, or if it does not actually sever it, so crushes it as to make all function or restoration of function an impossibility. This cutting or crushing of the cord takes place between the posterior upper border of the vertebra, next below the luxated one, and the arch of the dislocated vertebra, as illustrated in Case $\%$.

Another variety of fracture-dislocation is illustrated in Case 4 (Fig. 1) in which the contiguous surfaces of two vertebral bodies have crumbled under the forced flexion. The greatest pressure being exerted anteriorly, the anterior lips, superior and inferior, of the two vertebræ in question are chiefly concerned in the crumbling. A second result of the disposition of the pressure is the forcing backward of the intervertebral disc. This disc together with the bony detritus presses against the anterior aspect of the cord.

With forced flexion of the cervical spine, the head being pushed forward and down on the chest, the upper or luxated vertebra can slip forward, the posterior lips of the anterior articulating surfaces riding over the anterior lips of the superior articulating surfaces of the vertebra immediately below and becoming locked, as it were, in its superior intervertebral notches. The attenuation of the spinal foramen in this case, though pronounced, is not so complete as in backward luxation, unless the deformity be further accentuated by a crashing of one or both vertebral bodies, as in the case reported by Carson." When we reach the lumbar region, what with the increased thickness of the intervertebral discs and the great mobility of the vertebræ, particularly in flexion, we find that the bony obstacles to dislocation present in the thoracic region do not here obtain, and an anteroposterior displacement is not only possible but is rendered probable, if there be forced flexion of the lumbar spine at the time of, or consequent to the injury. Although, from a mechanical standpoint, it is theoretically possible to have a pure dislocation in the lumbar region uncomplicated by fracture, the lower vertebra slipping forward or backward, yet there are many who think that

4. Trans. Am. Surg. Assn., 1905. fracture almost always plays an important part in these injuries.

In the cervical and lower thoracic regions self-reducing dislocation without fracture frequently takes place. We are all familiar with the picture of a case of this kind. A man receives an injury to his spinal column. Careful examination fails to reveal any deformity, crepitus, ecchymosis or other signs of fracturc. But there is a partial or complete paralysis present of segmental nature. If this case comes to necropsy, there is found no bony lesion, there may even be a fair amount of firmness in the ligamentous binding, but the spinal cord shows signs of compression opposite an intervertebral disc. At times, this compression is so great that the cord appears as if a string had been tied around it.

There have been many who have advanced the theory that the spinal musculature was a preventive factor in dislocation. This, I consider, is erroneous. As far as prevention of dislocation or fracture-dislocation is concerned, the muscles play absolutely no part whatever. As an argument to uphold this statement, I would call attention to the fact that the most frequent point for fracture dislocation is between the fifth and sixth cervical vertebre. Let us turn to the anatomy of the muscles in this region. 'The muscles whose attachments lie directly over the junction of the fifth and sixth cervical vertebræ are the multifidus spinæ, the semispinalis colli, the complexus, the trachelomastoid, the transversalis cervicis, the cervicalis ascendens, the scalenus medius, the scalenus anticus, the rectus capitis anticus major, and the longus colli. Here, then, we have eleven muscular attachments covering this articulation on each side, twenty-two in all, and yet it seems to be the point of election for fracture-dislocation in the cervical region.

We find the spinous processes more frequently broken from the fifth cervical to the end of the thoracic vertebræ. Gurlt ${ }^{5}$ says that in the cervical region in less than one-quarter of all cases, and in the thoracic in more than one-half of all cases, the spinous processes are broken. In the thoracic region, on account of the peculiar tile-like arrangement of the laminæ, above referred to, when one lamina is fractured, usually several are fractured with it. This, of course, does not refer to gunshot fractures. The spinous processes in the lum. bar region, according to Gurlt, are fractured in Jess than one-eighth of all cases. As a rule, transverse and oblique fractures of the vertebral bodics are nearer the upper than the lower surface. Isolated fractures of the articular processes are extremely rare.

Although, as stated above, the muscles of the spinal column play no part in its protection from fracture, yet there are a number of cases on record where fracture has been caused wholly by muscular action. One of these cases, reported by Gurlt, happened in this peculiar manner. A sailor, going in bathing from the deck of a ship, dived and while his body was shooting downward, he realized that there was not enough depth of water for him to escape an accident. For this reason, and in order to save himself, he threw back his head with all his force as he struck the water and sustained a fracture in the cervical region. Another case, likewise reported by Gurlt, was that of a man violently insane who, for purposes of restraint, had to be tied in an armehair. In this position he made strenuous nodding movements of the head, endeavoring to loosen his bonds. He also sus tained a fracture in the cervical region. 
Philipeaux, ${ }^{6}$ in his fracture experiments on the cadaver, found that the most frequent point of fracture was between the eleventh and twelfth thoracic vertebræ, the fracture being the usual variety from posteriorly and above to anteriorly and below. Experiments of this nature on the cadaver fail so completely to reproduce the conditions prescnt in a spinal fracture accident, that this finding of Philipeaux' is not of great importance as a comparison to the statistics of spinal fracture-dislocation in the living subject.

Gurlt classifies fractures of the spine as follows: (1) Fracture of the first and second cervical vertebræ; (2) fracture between the third cervical and the second thoracic vertebræ; (3) fracture between the third thoracic and the second lumbar vertebræ; (4) those below the second lumbar vertebræ. He does not think that fractures of the first class are necessarily immediately fatal, unless there be a pronounced dislocation. He cites the case of a patient who lived eight days. These patients die because of making some sudden voluntary or involuntary movement which displaces the vertebræ or fragments and causes pressure on the upper cord or the medulla oblongata. Gurlt calls attention to the fact that in none of the cases he cites, in which there was a fracture of the odontoid process, was there also a tearing of the ligamentum transversum dentis, although in several cases there was considerable displacement.

$\mathrm{He}$ cites an interesting case quoted by Sir Astley Cooper. ${ }^{7}$ A syphilitic woman, under mercurial treatment, suddenly, while eating breakfast in bed, had her head fall forward on her chest and was dead. A fracture of the odontoid process was found. Another patient of Cline's ${ }^{8}$ had a fracture of the atlas, and for one year aided all neck movements with his hands in order to prevent injury to the medulla oblongata. In these two cases, and in five others, making seven in all, there was fracture of the first or second cervical vertebræ or both. One patient died instantly. Another patient lived two months. Two patients lived five months. Still another patient lived eleven months. Another lived twelve months and still another twenty-eight months. In only one of these cases was there any disturbance of the integrity of the joint between the atlas and the occiput. This joint is tremendously strong, as anyone can testify who has endeavored to remove the head at the occipito-atloid articulation. The dislocation of the atlas on the axis occurs in death by hanging. I present herewith, a photograph of such a dislocation involving both articular processes. This specimen is in the Mütter Museum of the College of Physicians. The case was one of suicide by hanging. The spinal cord was found crushed, although the spinal canal was not reduced in area at the point of luxation more than about one third (Fig. 2). In the cases enumerated by Gurlt, where the fractured odontoid process injured the medulla, it did so by the backward pressure of its lower fractured surface.

When fracture occurs involving the phrenic nerve, death is usually very sudden from paralysis of respiration. There are cases where the patient lives a longer or shorter time with only a partial inconvenience in breathing. This may point to a partial lesion lower down in the cervical region, but some untoward movement will convert a possible simple fracture to a frac-

6. Revue Médico-chir., t. $x 1,1852$, p. 178 . new edition, by Bransby Cooper, London, 1842, p. 536 .

8. A Treatise on Dislocations and on Fractures of the Joints, new edition, by Bransby Cooper, London, 1842, p. 533. ture-dislocation with involvement of the phrenic nerves, and the patient drops dead.

In injuries to the spinal column, the spinal cord can be injured in a number of ways. I have already mentioned the possibility of its being transversely squeezed, or even cut in two. There are also cases on record where the plane of injury is oblique rather than transverse. In one case, reported by Gurlt, the spinal cord seemed to be wedged into a longitudinal cleft in the posterior aspect of the body of the fifth cervical vertebra.

I herewith give the histories of nine cases of injury to the spinal cord. Six of these were consequent to fracture-dislocation. One case was caused by a gunshot wound. One case was a pure, self-reducing dislocation without fracture; and one was consequent to spinal concussion without spinal lesion. For the pathologic material of these cases I am indebted to Dr. William G. Spiller, who has most kindly put at my disposal the material bearing on this subject in his laboratory. One of these cases was reported by Dr. C. S. Potts, another by Dr. Spellisy, and a third by Dr. Spiller and Dr. Martin. In the clinical histories of these cases there will be noticed many statements that seem vague, indefinite and careless. There will frequently be apparent glaring omissions of data which, for the scientific consideration of the case in question, are most important. These shortcomings will be easily understood and condoned by those who realize how very faulty is the system of history taking in many of our large institutions where the resident physicians are constantly changing and rarely ever interested.

CASE 1.-Male, aged 25 vears, laborer, born in Italy, was admitted to the Polyclinic Hospital, Nov. 17, 1899, with the history that a bank of earth had fallen on his back. On examination there was discovered a paralysis of both lower limbs and loss of sensation up to a "short distance" above the umbilicus. There was likewise a prominence of "several of the lower dorsal vertebræ." At 11 o'clock that night Dr. Roberts performed a laminectomy under ether anesthesia.

Patient died July 27, 1903. No notes on his immediate antemortem condition can be found. The full postmortem record does not particularly bear on this study; therefore I shall not quote it.

This case had skilful surgical treatment at once. The kyphosis was reduced, and all refinements of technic were used. And yet, here, as in so many other similar cases, the element of uncertainty is present as to just how much of the future difficulty was due to the fracture dislocation and how much to an unavoidable manipulation of the spinal cord on the part of the surgeon.

The microscopic examination of the spinal cord by the Weigert hematoxylin method showed complete disintegration in the level of the sacral region. Opposite the seat of compression, the tenth thoracic vertebra, there is great destruction and distortion of the white and gray matter. There are large irregular areas of degeneration, a small amount of normal white matter being left, chiefly in juxtaposition to the gray matter. This is particularly so in the middle root zone on one side. There is also on one side a preservation of many normal white fibers situated between the posterior horn of gray matter and the periphery of the cord, in the area of the direct cerebellar tract. A segment above the tenth showed an intense degeneration in the columns of Goll, in the direct cerebellar tract and in Gower's tract. Marchi preparations show no system degenerations, but some black dots still remain along the blood ves sels.

CASE 2.-Man, aged 38 years, colored, married, born in Maryland, was brought to the Philadelphia Hospital from the Jefferson Hospital, where he had been for three weeks following an accident to his spinal column. With the exception of 
the facts that he had been a heavy drinker, and that he denied venereal disease, his past history is not relevant.

On June 7, 1901, while at work, he fell from a ladder a distance of thirty feet, striking on his back. He was taken to the Jefferson Hospital unconscious. He regained his consciousness late on the same day, but was delirious and had to be restrained by straps for three or four days. When he eventually became rational, it was found that there was complete paralysis, both sensory and motor, of the lower extremities, upward as far as the upper border of the pubes and encircling the body. Incontinence of urine and feces came on about one week after the accident, both micturition and defecation having been unimpaired up to this time. There was a very tender protrusion over the lower dorsal and lumbar vertebræ, which was the seat of severe pain on motion. There was a bed sore over the lower part of the vertebral column.

Dr. Spiller's notes, dated July 1, 1901, state that there was complete paralysis in the lower limbs, the patient being unable to move a muscle "even with the greatest exertion." The lower limbs were flaccid and without contractures. The knee jerk, Achilles jerk and Babinski reflex were all absent on each side. There was no priapism. Irritation of the sole of the foot pro. duced no toe movement, and the cremasteric reflex was not obtained.

Dr. Spiller's diamnosis was: "The man has signs of com. plete interruption of the spinal cord in the lower thoracic region. The probable cause of this interruption is fracture of the lower thoracic vertebra." On July 11, dulness, singultus and free perspiration were reported. On July 12 , it is recorded that hiceough had been present almost constantly, that there was pain in the umbilical region, and that on irrigation of the bladder much dark brown fluid and detritus returned through the catheter. The patient died at $8: 45 \mathrm{p}$. m. July 14, hiccough having been present constantly, except for short intervals, three days before death. There was much albumin reported in the urine.

I shall omit the general necropsy notes, with the exception of a quotation on the kidneys, ureters and bladder, to-wit: "Ureters dilated, especially on the left side, where ureter reaches size of index finger. Kidney enlarged, capsule adherent and adhesions to surrounding tissue. On removal of capsule, numerous abscesses were found in the substance of the kidney. Pelvis dilated, and both pelvis and ureter contain creamy pus. The right kidney enlarged, less than the left; capsule peels readily; no abscess in cortex. Bladder is distended; contains thick yellowish pus."

From Dr. Spiller's dictation at the autopsy I quote the following: "The scar of an old injury, $4.8 \mathrm{~cm}$. Iong, the cicatrix of which is directly over the spine of the eleventh thoracic vertebra, extends on to the tenth and twelfth vertebra. The spinous process of the tenth vertebra is driven downward. The surface edge shows an irregular loss of substance, affecting also the entire superior surface. The interval between the tenth and eleventh spinous processes is increased. Beginning 5 millimeters from the superior surface of the spine there is an irregular fracture line extending laterally on each side and passing through the corresponding laminæ. The right lamina is prominent and shows the chief injury. The fracture on this side extends downward and forward through the entire diameter of the lamina. The tissues about the lamina are edematous and slightly hemorrhagic. On the left side the tissues are involved to a slighter extent, but the remains of the hemorrhage are found in the fascia and spinal muscles. The fracture extends through the upper portion of the body of the tenth thoracic vertebra, so that the two portions of the vertebra move freely one on another. The spinal cord apparently is completely compressed at the line of fracture, and is softened for a distance of $4 \mathrm{~cm}$. above the line of fracture. The softening at the line of fracture may have been produced at the autopsy.

The cervical region shows no gross lesions. The dura below the line of fracture is much injected, much more so than above the line of fracture." Spiller founds his paper," "The Sensory Segmental Area of the Umbilicus," on this case.

9. Phila. Med. Jour., Feb. 8, 1902.
I wish to call attention to the urinary condition in this case. In many cases of fracture-dislocation involving the lower thoracic region of the spinal column hematuria is a common symptom. This is, at times, caused by trauma to the kidney substance. But there are likewise many of these cases in which the kidney is uninjured and yet hematuria comes on the second, third, or fourth day, or even later. Wagner and Stolper, ${ }^{10}$ in speaking of the temporary suppression of urine often seen immediately following spinal fracture, advance the theory that this suppression is due to the fact that consequent to the attraction of blood to the lower limbs, on account of the vasomotor palsy of these parts, there is produced in the kidney substance a traumatic anemia. This anemia causes a great lowering in vitality in the kidney parenchyma which procceds in many cases to the absolute death of the epithelium lining the tubules. These investigators found this condition of affairs two hours after the accident.

It seems to me that the hematuria above referred to may well be explained on the same hypothesis: The vascular equilibrium boing restored the kidney finds itself supplied with blood, which, on account of a badly damaged parenchyma, it can not handle, and hence the hematuria. I have recently seen this picture in a dog, a portion of whose spinal cord I cxsected in the midthoracic region. In this animal the hematuria set in on the fourth day after the operation.

CASE 3.-Man, aged 56 years, carpet weaver, born in England, was brought to the Philadelphia Inspital thirty-six hours after falling down stairs. Regarding the decubitus, I quote as follows: "Patient, well-nourished man, lies with fingers flexed, forearm flexed on the arm, the arms elevated about 15 degrees from the body." A slight power of flexion and extension at elbow was preserved, and he conld elevate the upper extremities to right angles with the trunk. The act of pronation and supination of the forearms seemed to be accomplished by the biceps muscle, as there was no contraction of the supinator longus when this motion was excented There was no paralysis in either upper or lower extremities. The plantar reflexes were slight, the big toes flexing. The knee jerks, Achilles tendon jerks, cremasteric, epigastric and abdominal reflexes were all absent. The cilio-spinal reflex was present. There was a marked retraction of abdominal museles in respiration. At times his penis became partially erect. The patient complained of pain in the back of the neck. There was a tenderness extending over the seventh cervical and first thoracic vertebræ. A bed sore had begun over the right trochanter and also one over the scapula. The prick of a pin was followed by a persistent hyperemia of the skin. The patient could slightly rotate his arms outward.

At the postmortem examination a fracture of the skull was discovered over the left parietal and temporal bone, beneath which was an extradural blood clot, $8 \mathrm{~cm}$. in diameter and having a maximum thickness of $1.5 \mathrm{~cm}$, situated mainly over the motor area. There was no subdural hemorrhage and the ventricles were normal. The spinal cord exnibited a depression which corresponded to the body of the fourth cervical vertebra, which had been slightly displaced backward. The depression was so deep that the cord appeared as if entirely severed. Dr. Spiller's notes read: "Compression seems to be between the sixth and seventh cervical segments. There were sensory disturbances in the distribution of the fifth cervical segment."

This case is interesting for a number of reasons. In the first place, the mechanies of the fracture-dislocation was the backward displacement of the cervical vertebra, to which I referred in my general considerations. The case was made the subject of a paper by

10. Die Verletzungen d. Wirbelsäule u. d. Rückenmarkes, Deutsche Chir., No. xl, 1898. 
Dr. Charles Potts, ${ }^{11}$ whose patient he was, discussing the location in the fifth cervical segment of the biceps tendon reflex. Now, bearing in mind that there was complete solution of continuity of the cord at the fifth cervical segment, there was retention of normal plantar reflex and abolition of all the other reflexes of the lower limbs. Also he had partial erection of the penis at times.

The peculiar position assumed by the arms in this case coincides with the position depicted by Thorburn ${ }^{12}$ in a fracture-dislocation involving the same segment of the cord. The extrome crushing of the cord in this case is

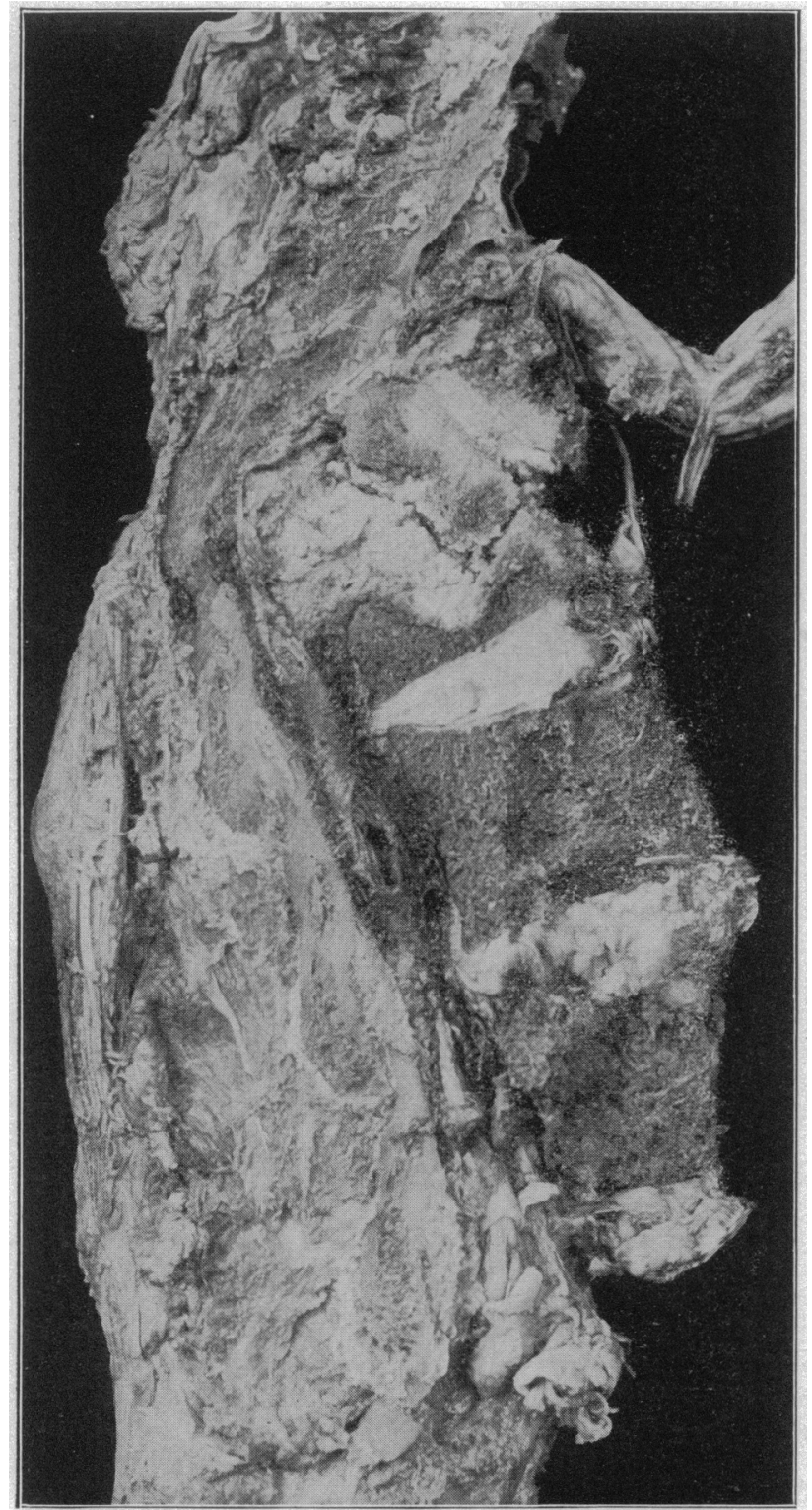

Fig. 1.-Case 4. Fracture-dislocation of the ninth and tenth thoracic vertebræ.

owing to the remarkable attenuation which the cross section of the vertebral canal suffers in these cases where the displacement is backward in the cervical region.

The question of the preservation or loss of the plantar

11. A Case of Traumatic Cervical Hematomyelia and Complete 11. A Case of Traumatic Cervical Hematomyelia and Complete Division of the Cold, with Probable Dislocation of the Fifth Cer-
vical Vertebra, Remarks on the Location of the Center for the vical Vertebra, Remarks on the Location of the Center for th
liceps Reflex, Jour. Nerv. and Ment. Dis., 1905, vol. xxxii. p. 359. 12. A Contribution to the Surgery of the Spinal Cord. 1889. reflex in cases of complete lesion of the spinal cord is, at present, a model one. J. J. Thomas ${ }^{13}$ says that in complete transverse lesion of the cord the plantar reflex is often retained.

Unquestionably, the majority of cases of complete transverse lesion reported have abolition of the plantar reflex. There is probably some other equation in the preservation or loss of this reflex other than complete solution of continuity.

The question of erection of the penis in cases of spinal cord injury is possibly more unsettled than it was a few years ago, when it was generally accepted that the center of erection and ejaculation as well as for the detrusor of the bladder and the rectal mechanism were all located within the cord. Lately some evidence points to the fact that these centers are largely, if not wholly, extraspinal, being possibly in the hypogastric and hemorrhoidal plexuses of the sympathetic. There are, nevertheless, many who defend the intraspinal location of these centers. ${ }^{14}$ Wagner and Stolper speak of priapism in cases of injury to the spinal cord as of purely vasnmotor origin when the lesion is above the erectile center. This center they locate in the second sacral segment. They differentiate between erection in the sensual sense and a soft, semi-flaccid turgescence. The former depends on a stimulation of the motor neurones for the ischiocavernosus, transversus perinei, and bulbocavernosus muscles. The soft turgenscence, with our incomplete knowledgc, only points to a spinal lesion. In other words, we are unable to say that the one symptom points to complete transierse lesion, the other to incomplete.

CASE 4.-Man, age, nativity, ete., unknown, was admitted to the Philadelphia Hospital, Feb. 13, 1903, with the history that about ten months prior to this date he was crushed, an injury to his spine resulting. Since this time any motion involving the spinal column caused pain. His knee jerks were exaggerated, ankle clonus was present and the Babinski reflex was obtained on the right side.

With a few minor exceptions, there is a gap of almost two months in the history. On April 10 it is entered on the chart: "Patieiz operated on at $1: 30 \mathrm{p} . \mathrm{m}$. An incision over dorsal vertebræ was made about eight inches long and a laminectomy done." Just why this patient was operated on is not indicated. There is no history, recorded or unrecorded, that he was getting worse prior to the operation. A vertebra was found displaced and rotated, to which the cord was bound on the left side of the canal by dense adhesions. The cord was found to be softened at the site of the luxated vertebra. On April 11 (the day after the operation) it is noted that the patient on examination showed a loss of sensation in the left leg and the lower third of the thigh; also in the right leg to the knee. Also, "Patient is unable to move toes of either foot." On April 16 it is noted that the patient seemed unimproved. It was necessary to catheterize him since the operation, and his bowels would not move without an enema. It was impossible to keep the skin on the patient's back in a healthy condition. On April 19 the patient was still unable to void urine voluntarily, and this retention obtained until October 25 , when it is noted that incontinence had occurred. On May 2 it is recorded that he "can not move lower extremities at all."

Here occur great gaps in the history, with a few unimportant observations. I quote Dr. Spiller's notes of July 23, 1904, ten days before the patient's death: "lower limbs are extremely wasted. The only movement possible is a slight drawing upward of the limbs on either side, but there is no flexion of either limb.

In a long postmortem record there is noted: "Necrotic ab-

13. Five Cases of Injury of the Cord, Resulting from Fracture of the Spine, Med, and Surg. Reports of the Boston City Hospital, Series $x i, 1900 . \mathrm{n} .1$.

14. E. Reichert, in a personal communication. 
scess formation of seventh, eighth and ninth dorsal vertebræ." The microscopic examination of the spinal cord shows by the Weigert hematoxylin method well-marked degeneration in the columns of Goll, in Gowers' columns and in the direct cerebellar tract (Fig. 3). The method of Marchi shows degeneration in Goll's column and also a few black dots in Gowers' column on the right side. Numerous fat crystals were found in the solumns of Goll above the lesion in the Marchi preparation, which I shall discuss elsewhere.

It appears evident that, on admission to the hospital, the patient had not an absolute solution of continuity in the spinal cord, in fact there must have been a goodly amount of normal functionating axons bridging the seat of injury to account for the amount of motor and sensory function still intact. The fact that this condition of affairs obtained ten months after the accident should be enough to warrant the prognosis that the acute degenerative changes had extended as far as they were going to cxtend, and barring future trauma and the very slow sclerotic changes, the probabilities were that he would have remained in statu quo. The operation in this case, can not therefore be defended by even the most radical advocates of the knife.

The injury the surgeon is able to do to the spinal cord in these cases is here demonstrated beautifully. From a chronic condition, at rest, the case was converted

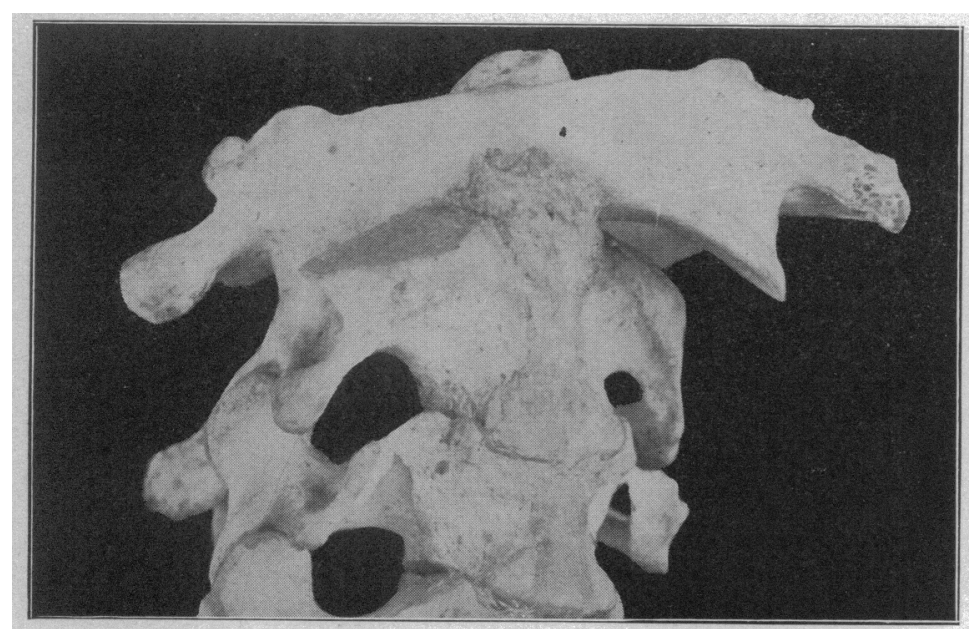

vertebræ, also between second and third dorsal vertebræ. Transverse fracture of sternum. . . . The musculature over the sixth, seventh and eighth cervical vertebræ infiltrated with blood. . . . The part of the cord overlying the fracture is slightly compressed and softer in consistency than portions either above or below." Here follows a rather involved description of a fracture of the skull, the exact localization of which is not evident, but which is obviously considerable in extent from this quotation: "Subdural hemorrhage in the left anterior fossa, left middle fossa and right posterior fossa. There is an irregular macerated area involving the inferior frontal and middle convolutions of the left side."

Sections were made from the second or third, the sixth, seventh and eighth cervical regions and also from the first and second thoracic regions. They were stained by the hemalum acid-fuchsin and Weigert's hematoxylin methods. The sections from the highest block of tissue, either second or third cervical, appeared normal. At the level of the sixth cervical segment there appears a hemorrhage in the gray matter on both sides of the cord and also in the anterior commissure. These hemorrhagic foci are all distinct and separate. There is great injection of the anterior central branches of the anterior spinal artery, and in the eighth cervical segment this pressure has been so great that there appear minute areas where the red blood corpuscles have broken through the wall

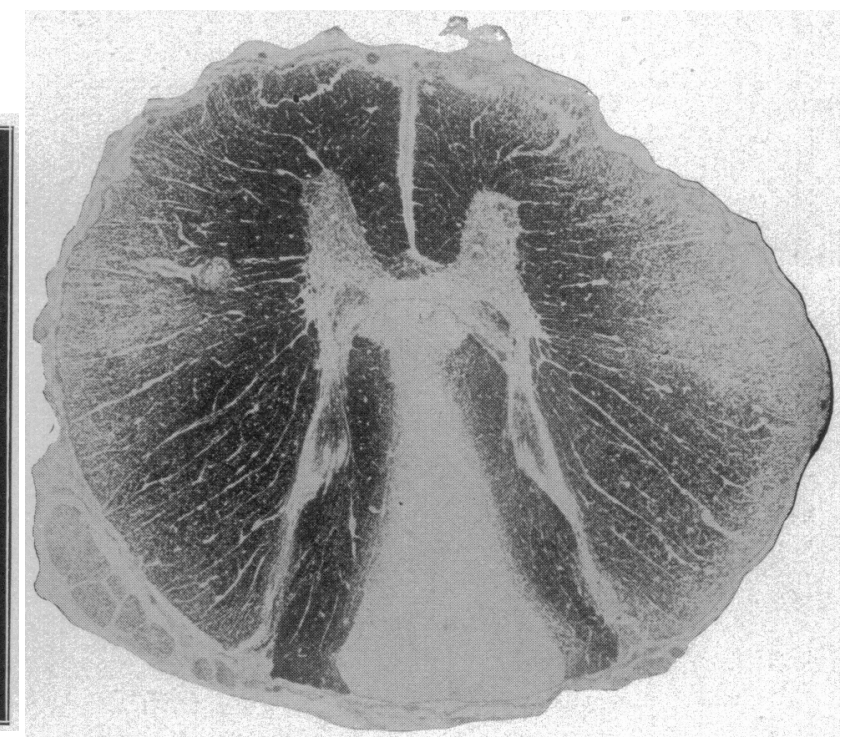

Fjg. 3.-Case 4. A section of the spinal cold in the mid-thoracic region showing intense degeneration in the columns of Goll and also some degeneration in the direct cerebellar and Gowers tracts. (Weigert preparation.)

the axis. Suicide by hanging (Specimen from the of the atlas on College of Physicians, Ihiladelphia.)

again into an acute condition, the results of the operation being loss of bladder and rectum control, loss of motor and sensory function, and a tendency to bed sore formation.

CASE 5.-Man, aged 59 years, colored, born in Delaware, was admitted to the Philadelphia Hospital, Jan. 2, 1905, with the history that he had fallen from a wagon and had struck on his head. After the accident he was able to walk with assistance for about one hour, when his lower limbs became completely paralyzed. He had a loss of tactile and temperature sensation in the lower limbs and on the trunk extending up to above the third rib. Above this there was a band of hyperesthesia. He was able to move his arms, but was unable to flex his fingers or move his thumbs. His third rib on the left side was "dislocated" at its sternal junction. He answered questions coherently. He had, on admission, retention of urine and feces and complained of pain in his neck. There are no further notes on the case during life. The patient died January 3.

The following is quoted from the postmortem record: "Fracture of sixth cervical vertebra, body. Fracture of the laminæ of the fifth and sixth cerevical vertebræ. Ligamentous rupture between sixth and seventh spinous processes of the cervical of the blood vessel and are lying free in the anterior fissure. In the upper part of the seventh cervical segment the hemorrhages found in the segment above are not present. There exists here simply an overdistension of the central branch of the anterior spinal artery, with a leakage from this vessel of red blood cells into the margins of the anterior columns of the cord.

In the lower part of the seventh cervical segment there is a rupture of an artery in the anterior gray commissure, the hemorrhage extending directly backward into the posterior columns for about one-fifth their depth. There is also in this level a very minute hemorrhage in the center of the gray matter of one anterior horn and the central branch of the anterior spinal artery is greatly distended. In the eighth cervical segment the entire gray matter is hemorrhagic, the extravasations extending into the contiguous white matter. The first thoracic segment is the same as the eighth cervical, except much more pronounced and here there seem to be hemorrhagic processes in the white matter of the lateral and posterior columns (Fig. 4). In the second thoracic segment the hemorrhage is not found in the white matter and, except for one minute focus in one anterior horn, is confined altogether to the other anterior horn. 
This case brings up the very interesting subject of traumatic hematomyelia. This condition is frequently found in cases of fracture-dislocation where the spinal cord has been pressed on; it is also found in cases of severe spinal concussion where there has been no fracture and no crushing violence to the spinal cord. Much speculation has existed as to the cause of traumatic hematomyelia and why the gray matter is so preponderatingly chosen as the seat and limit of the hemorrhage. As a rule, the hemorrhage is not multiple and although found in different parts of the gray matter in different levels of the cord, still, if examined in serial sections, a continuity will often be demonstrated among the several seemingly separate foci. Pearce Bailey has published a classical case of multiple hemorrhages into the cord.

The consensus of opinion seems to be that the hemorrhage is caused by the commotion in the cord substance, and is located in the gray matter on account of its weaker and softer consistence. That the gray mat- youth, of knocking together two stones under water when another boy is completely submerged demonstrates on our tympanum the absolute incompressibility of liquids and the terrific force which can be brought to bear by a seemingly insignificant means. Although the blow usually comes on the posterior aspect of the spinal column, yet the greatest hydraulic action is felt in the anterior spinal artery because of its being a more direct and straight blood channel than any found on the posterior surface of the spinal cord. The difference between the posterior and anterior blood supply to the spinal cord I have referred to elsewhere. ${ }^{15}$

It seems to me the views of $\mathrm{Kadyi}^{16}$ that the small arteries of the anterior fissure pass to one side or the other, rarely bifurcating, explain why it is that one finds in serial section study of a case of traumatic hematomyelia the so frequent shifting of the seat of hemorrhage from one side to the other. Without doubt the hydraulic pressure extends over a distance sufficiently

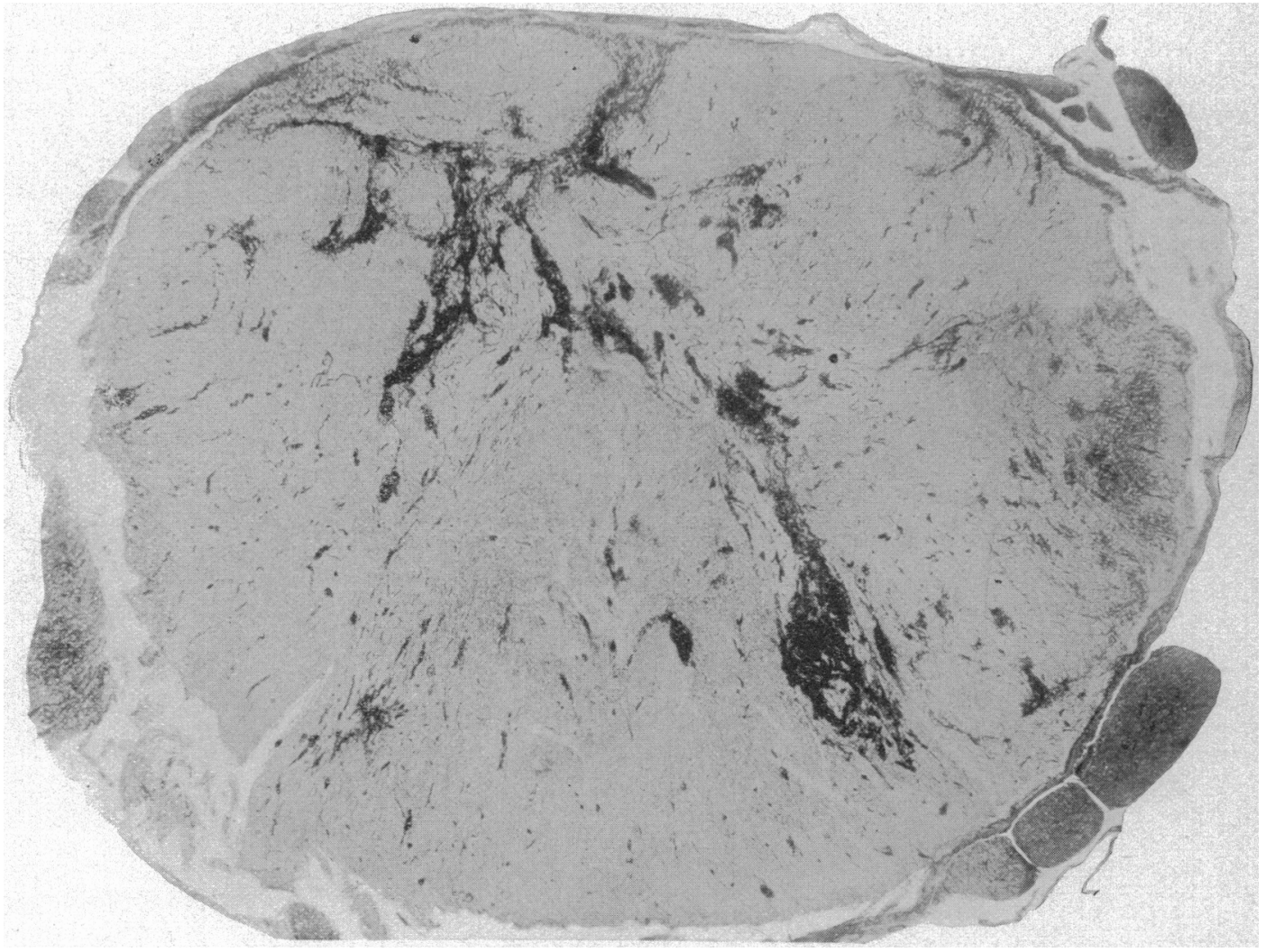

Jig. 4.-Case 5.-A section of the spinal cord at the first thoracic segnent. showing intense hemorrhagic condition. (Weigert preparation.)

ter has less cohesive strength is axiomatic. But I take it that the hemorrhage in traumatic hematomyelia is of purely hydraulic origin. There is usually in these cases a marked flexion of the spinal column, and consequent forcing of blood into the anterior fissure of the spinal cord. As this causes an hydraulic expansive force in the central arteries from the anterior spinal artery, and as the distribution of these arteries is practically wholly within the gray matter, the reason for usual limitation of the hemorrhage to the gray matter is obvious.

My explanation for those cases of traumatic hematomyelia where there has been simply concussion of the spinal column without hyperflexion or fracture is likewise on the hydraulic hypothesis. That homely and painful practical joke, in which we have indulged in great to take in at least two of these median branches from the anterior spinal artery.

CASE 6.-Man, aged 32 years, a miner, born in Italy, was brought to the Philadelphia Hospital on Dec. 22, 1905, suffer. ing from a paralytic condition consequent to a gunshot wound of the spinal column received two months prior to admission. His past history was negative. He denied venereal infections, but owned to having used a great deal of alcohol without ever becoming "very intoxicated." The point of entrance of the bullet was just above the insertion of the deltoid muscle in the left arm. The humerus was fractured. On receipt of this injury he fell, having no power in his lower limbs. One month after his wound he began to have shooting pains in his lower limbs and a bed sore began to develop over his sacrum.

15. Combined Pseudosystemic Disease, with Special Reference to Annular Degeneration, Univ. of Penna. Med. Bull., January, 1905. 16. Ueber d. Blütgefässe d. Menschlichen Rückenmarkes, Isem berg, 1899 . 
On January 2, after an $x$-ray examination, in which the bullet was located, the patient was operated on, an exploratory laminectomy being done. The fourth, fifth and sixth thoracic spines were removed, but the bullet was not found. The patient lived until February 22. During this time he gradually grew weaker. The wound proved very refractory and there remained several sinuses leading to the spinal cord.

The history records, after the operation, an incontinence of urine and feces, but whether this condition obtained before the operation is not indicated, but probably it did. There is also noted on February 10 that there was a "large bed sore over the right hip, exposing the trochanter and eight inches of the shaft of the femur."

At the autopsy the bullet was found imbedded in the body of the fourth thoracic vertebra, where it had been located by the $x$-ray.

The microscopic examination shows an intense degeneration by Marchi's method at the level of the lower part of the pyramidal decussation in Goll's columns, in the direct cerebellar columns and in Gower's columns. In the eighth cervical segment there is a degeneration of some of the anterior cornual cells, also there is seen here by Weigert's method degeneration in the columns of Goll and the direct cerebellar and Gowers'

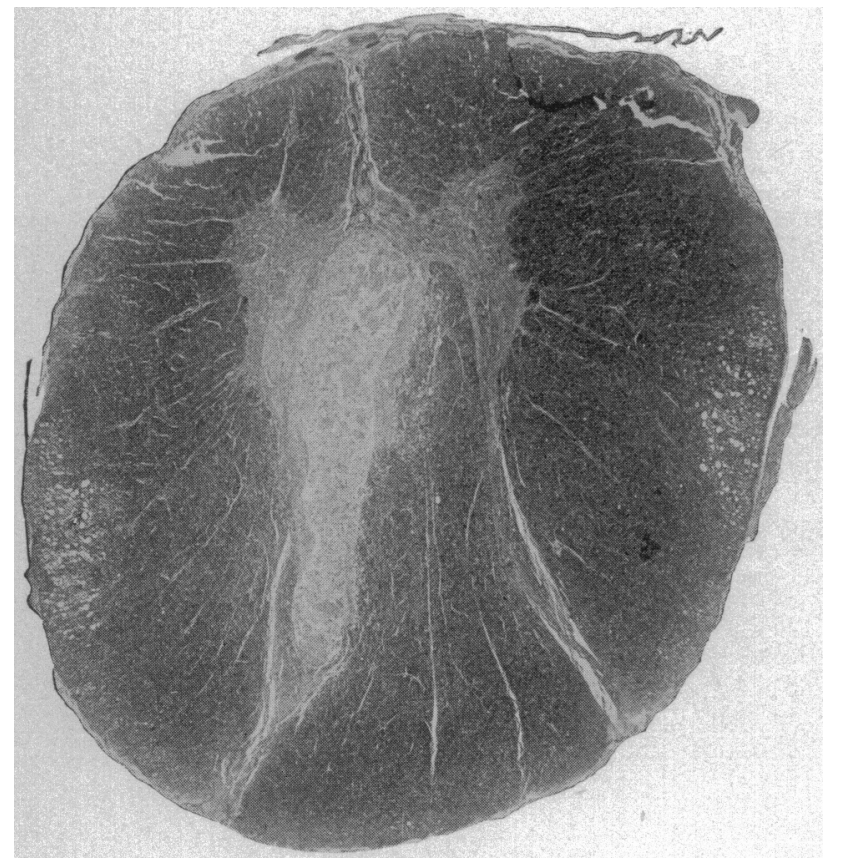

Fig. 5.-Case 7. A section of the spinal cord about $2.5 \mathrm{~cm}$. (fourth block) below the seat of compression, showing area of central softening and two areas of degeneration peripherally and symmetrically situated. (Weigert preparation.)

tracts. Both Weigert's hematoxylin and Marchi preparations show degeneration in both crossed pyramidal tracts in the lumbar region. Sections from the seat of compression show complete disintegration of the spinal cord, only a few irregularly scattered groups of axis cylinders remaining normal and intact, and these mostly at the periphery of the spinal cord. The degeneration, when followed up into the medulla by the Marchi method, shows very beautifully the parting in different directions between the direct cerebellar tract as it swings back into the restiform body and Gowers' tract, continuing upward.

This case introduces an important point which is frequently brought up in arguments pro and con laminectomy in cases of spinal fracture-dislocation. One of the chief reasons advanced by the surgeon or surgically inclined neurologist for operating in these cases is, as Burrell says, "that if pressure on the cord is allowed to remain for many hours, irreparable damage to the cord may take place." This statement would infer that the immediate removal of pressure would tend to prevent the "irreparable damage to the cord," which idea is wholly fallacious. The spinal cord in this case had barely been grazed by the bullet, the dura mater being intact and without abrasion. The bullet had lodged in the vertebra and was exerting no pressure whatsoever on the spinal cord. Therefore, whatever injury obtained resulted from the instantaneous pressure of the bullet in passing, a pressure indenting possibly the dura but not enough to abrade or tear it, and then absolutely removed. And yet, note the wholesale destriuction of cord tissue in this case. It seems to me that in weighing your data pro and con operation in these cases, the pressure of fragments should not be the reason for a rapid operation. If a fragment has exerted pressure sufficient to cause degeneration, that degeneration will take place and be as immutable one second after the reception, of the injury as it would be one week after. When the dura was opened in this case the cord was found completely softened.

CASE 7.-Man, aged 38 years, an iron worker, born in America, was brought to St. Joseph's Hospital, Oct. 14, 1906. Dr. Spellisy, whose patient he was, has kindly furnished me with the following brief facts: The family history was negative, as was also his past history. On the date of his admission he was working on a scaffold, when it gave way and he fell a distance of thirty feet. What part of his body struck the ground is not known. He did not lose consciousness, but was unable to get up. He complained of pain in his arms and

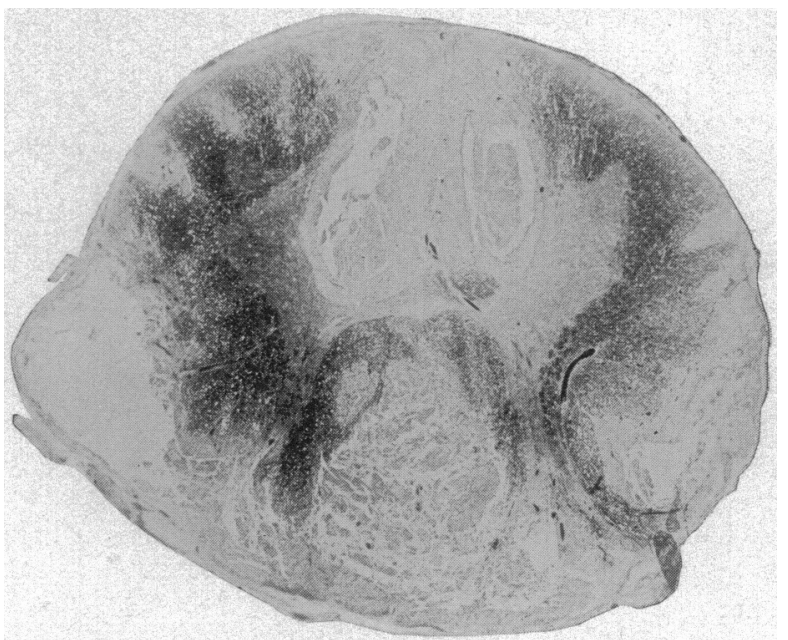

Fig. 6.-Case 8. A section of the spinal cord immediately above the seat of compression, showing intense degeneration and disin. tegration of cold substance. (Weigert preparation.)

upper part of back. This pain he described as like red-hot irons going through his arms.

He was a well-nourished and well-built man. There was loss of sensation up to the second rib, the limiting line of anesthesia circling the body horizontally. He had retention of urine and incontinence of feces. There was a slight laceration of the scalp. The eyes were normal. The loss of the sense of pain extended above the loss of tactile sensation. Knee jerks and plantar reflexes were absent. There was a loss of the power of the flexors of the fingers. The patient gradually lost ground and died October 31 .

I received the pathologic material in the shape of a portion of the spinal column, including two vertebræ below the point of fracture-dislocation and six vertebræ above. Judging from the topography of the gray and white matter of the highest segment, the legion involves the upper part of the thoracic cord. For a distance of about four centimeters the cord is absolutely softened, having been nipped between the posteriorsuperior edge of the vertebral body next below the Iuxated vertebra and the arch of the dislocated vertebra. From a point one and a half centimeters below the point of constriction to fully five centimeters distal there was an area of soft- 
ening occupying the posterior part of the left anterior horn and extending backward into the posterior horn to within a short distance of the periphery.

The three and one-half centimeters of cord were divided into five pieces and mounted in celloidin and cut. They were num. bered from below upward. Block 5 shows an area of degeneration in the white matter at the periphery on the side opposite to the cerebral softening. This area is small and is situated at what might be tha junction of the direct cerebellar and Gowers' tracts. In Block 4 (Fig. 5) there is, in addition to this same area, a similarly situated area of degeneration on the other side. These areas are true degenerations, showing swollen axis eylinders. They were probably caused by the injury inflicted to the cord by stretching it over the posterior surface of the body of the vertebra next below the vertebra luxated. In Block 3 this degeneration is not present. The photomicrograph shows the area of central softening together with the degenerations as found in the fourth block. Had it been possible to cut and stain an entire unbroken set of serial sections through this part of the cord, doubtless one would have found occluded or damaged blood vessels to account for the central softening.

CASE 8.-A young student was brought to the University Hospital, March 15, 1906, with the following history: He had been wrestling in a gymnasium, and his opponent, having gotten his head on the mat, was endeavoring to force the shoulders down also. Without any sudden wrench the patient collapsed and was in a perfectly limp condition. Afterward he stated that he had experienced a sensation as if something had broken. There was diaphragmatic breathing, motor and sensory paralysis, the area of anesthesia extending well above the umbilicus, and there was also priapism and loss of reflexes. The grasp of each hand was weak, but the motions of the arms at the shoulders were normal. There was tenderness on pressure over the sixth cervical vertebra, but no deformity.

The patient died, March 30, from "pulmonary edema and general exhaustion."

Operation was not resorted to in this case, owing to the hopeless outcome which was indicated. In a letter to Dr. Spiller, Dr. Edward Martin, who also saw the patient in consultation, said: "I have not accentuated a feeling that I had then and still have, that it is a rather goot thing to go into these absolutely hopeless cases on general princinles with the idea of finding, perhaps, the one in a thousand who can be helped."

The autopsy discovered a luxation of the seventh cervical vertebra which had been reducel spontaneously. There was no fracture. The cord had been completely crushed. Dr. Spiller's notes were as follows: "There was an adhesion between the posterior part of the dura and the lower part of the seventh cervical vertebra. The seventh cervical vertebra was a little displaced on the first thoracic. There was a slight protrusion backward of the body of the seventh cervical vertebra which was visible when the cord was removed. The body of the seventh cervical vertebra was very movable. No hemorrhage anywhere. The cord was swollen above and below the seat of compression. The compression is very marked and is at the extreme upper part of the eighth cervical segment.

Sections for mieroscopic examination were made immediately above the level of the compression (Fig. 6). There were areas of softening in the lateral, posterior and anterior columns on both sides, together with a great comminution of the white matter. Only the part of the cord immediately involved at the seat of injury was allowed to be taken at necropsy. This case was presented by Dr. Spiller and Dr. Martin before the Philadelphia Academy of Surgery.

This case may be classified among the pure dislocations. As stated, it was self-reducing. The injury was completed in the twinkling of an eye, and yet, note from the picture the obvious cord destruction. This appearance is typical of this class of injury, the cord looking as though it had been constricted by having a string tied around it. The terrible destruction of tissue above and below the seat of injury is shown in the accompanying illustration. Although the history records priapism as a pronounced symptom, I am told by Dr.
Spiller that somi-flaccid turgescence would more accurately described the condition.

The following case was reported by Dr. Spiller. ${ }^{17}$

CASE 9.-A man, aged 46 years, fell eight feet out of a window and struck on his face. He remained on the ground unconscions for several hours after his fall before being found. His examination revealed that he had no control over his bladder and rectum. He could draw up his lower limbs, but the movement was much impaired. The knee jerks were present, but not exaggerated. The Babinski reflex was uncertain. The voluntary movement of the upper limbs was much impaired. He could not move the fingers of either hand, but could move his arms at the shoulder and elbow joint imperfectly. Sensation for touch was normal all over the body. The sensation for pain and temperature was much impaired in the lower limbs and over the trunk anteriorly and posteriorly as high as the base of the neck. There was also some impairment of pain and temperature sensation in the upper limbs, but not so much as in the lower.

The seventh day after his accident the patellar tendon reflex on the left side was absent and on the right was feeble. The Babinski reflex was present on both sides. The fourteenth day after the accident it is recorded that the restoration of power to the lower limbs was remarkable. On the thirtieth day after the accident he could make feeble extensor and flexor movements of the fingers of each hand. He died thirty-eight days after the accident.

In this case were found two distinct foci of disease: First, a traumatic myelitis which Spiller defines as a degeneration affecting the nerve cell body and the nerve fiber, together with a round-cell infiltration, proliferation of neuroglia, congestion of blood vessels and miliary hemorrhage. This affected the fourth, fifth and sixth cervical segments. Second, a degenerative change in the cell bodies of the anterior horns which was much greater in the eighth cervical segment than elsewhere. The hemorrhages were too minute to be detected with the unaided eye.

On account of the findings in this case Spiller says he considers that it is impossible to make a differential diagnosis during life between hematomyelia and traumatic myelitis.

'The limitation of time and space prevent me discussing spinal localization, the reflexes and motor and senscry paralysis.

The treatment of a case of spinal fracture-dislocation if often rendered much more difficult than it otherwise would be by reason of the ignorant ministrations of the well meaning laity present at the time of the accident. When a man receives an injury of the back which renders him unable to arise, he should be carefully placed on a fiat stretcher, preferably one extemporized by boards and not soft and yielding. Care should be taken to preserve as nearly as possible the position of the body as originally found after the accident, unless the position threaten life. This can only be done by bolstering up certain parts with pillows or better still extemporized sand-bags or mounds of earth. Absolutely no attempt should be made to straighten out his body until his clothes have been cut from him, and then only by an experienced physician. After the patient has been duly examined, it is well to pass a catheter as soon as possible, under strict aseptic precautions, and empty the bladder. In this way one is able to judge more accurately of the functional ability of the kidneys during the first twenty-four hours. If the patient be delirious norphin is indicated to counteract a restlessness which might displace a fragment of bone and so wound the cord. If given hypodermically, care must be taken not to give it in an area which shows a circulatory stasis or

17. American Neurological Association, 1902, Traumatic Lesions of the Spinal Cord without Fracture of the Vertebræ. 
edema, otherwise there will ensue very slow and imperfect absorption and trophic changes might occur.

The question of operation will always be much discussed. I wish to note a few of the justifications which have been advanced for operation in these cases. Tubby ${ }^{18}$ says, operation is indicated if there be "pressure from fractured laminæ, or from a process driven inward, or a spicule of bone perforating the theca and cord, hemorrhage and when the cauda equina and lumbar sacral plexuses of nerves are implicated." McCosh ${ }^{19}$ says, "(1) The risk of the operation of laminectomy is slight. (2) Eariy operation is of the greatest importance. Operate before the onset of degenerative changes. (3) . . . (4) Operate rapidly. Employ but few artery forceps or ligatures. (5) Support of the spinal column after operation is generally unnecessary." Burrell says, "An open operation gives definite information as to the condition of the cord and, above all, allows pressure to be removed." Haynes ${ }^{20}$ says that all patients who survive the shock of the injury to the spinal cord and its complications should, in gunshot cases, be operated on. The following are the conditions which he thinks demand laminectomy: "(1) To remove the bullet, or spiculæ of bone or particles of clothing; (2) to remove blood clots; (3) to arrest hemorrhage; (4) to allow oozing in traumatic edema of the cord; (5) to prevent pressure and sepsis by drainage; (6) in advancing paralysis; (7) to suture a severed cord." Oliver says to operate where there is "some acute function of the spinal cord. In other cases, those in which there is no such evidence, it is highly probable that nothing is lost by waiting two or three days." Munro suggests a union of the roots above and below the injury in cases where there is division of the cord. Horsley advises waiting a few days and then operating to remove fractured laminx or projecting portions of the vertebral bodies or at times intervertebral dises.

Tubby's argument as to pressure I have answered above (Case 6). To McCosh's advice relative to the slight risk of laminectomy in spinal fracture-dislocation cases, I can only say that literature teems with cases whose future course after operation is the strongest denial of that statement. No matter what good is to be done mechanically, there is no denying that to operate is to convert a simple into a compound fracture, and the risk of such a measure can never be spoken of as slight, no matter how skillful or aseptic is the operation. As to Burrell's statement anent the definite information concerning the condition of the cord which we gain by open operation, it is really hard to take that seriously. If there is one thing that a laminectomy frequently fails to do, it is to give much or at times any clue to the condition of the cord. (Case 6.)

Spiller ${ }^{21}$ answers Haynes' argument in favor of operation by calling attention to the fact that srme authorities consider the symptoms of compression due in reality to secondary degeneration. He thinks, moreover, that the removal of an external clot on the cord is of doubtful value, and he questions the good influence of an operation on an edema of the cord following fracture or injury of the spine. 'The seventh point taken up in Haynes'

13. Injuries to Spinal Column and Spinal Cord, Clin. Jour., vol. xxiv. No. 25,1904, p. 385.

i9. Remarks on Spinal Surgery with Illustrative Cases, Jounsat A. M. A., Nos. 9 and 10 , vol. xxxvii.

90. Gunshot Wounds of the Spinal Cord, a Plea for Early Myelorihaphy, with Report of a Case of Bullet Wound Through the Liver, Spinal Column and Cord; Laparotomy; Laminectomy: Recovery: N. Y. Med. Jour.. Sept. 22, 29.1906.

21. Keen's System of Surgery, vol. ii, 1907. argument, i. e. "to suture the severed cord," need not be discussed, except to say that the entire weight of all careful observation and evidence is against the possibility of the cut ends uniting so that there ever will be functional continuity between the two ends. This takes into account the several alleged cases of spinal cord suture with partial return of function afterward. M. Allen Starr, ${ }^{22}$ denies that repair of the spinal cord ever occurs. He says that scar tissue may form, but that "restoration of continuity of the nerve fibers" is impossible. He gives the weight of his opinion against operating saying that the results are "uniformly disappointing."

Oliver' $\mathrm{s}^{23}$ advice to operate where there is "some acute function of the spinal cord" remaining seems to me diametrically opposed to reason. If one be fortunate enough to have an incomplete lesion of the spinal cord following a fracture-dislocation why run the risk of converting it into a complete lesion as in one of my cases quoted above (Case 4)?

Munro's ${ }^{24}$ suggestion of suturing the nerve roots immediately above the lesion to those immediately below is fantastic only because of our lack of experimental clata in this direction. He evidently advances that means, accepting the doctrine that axon regeneration is dependent on the nuclei of the neurilemma and can never take place in a cord suture, the cord lacking neurilemma.

The work of Kilvington ${ }^{25}$ has lent additional weight to Munro's suggestion. This investigator (Kilvington) sutured in a dog, the central ends of spinal nerve roots ieading to the hind limbs to the peripheral ends of the nerves to the rectum and bladder, with successful results. He thinks that nerve crossing would not be feasible in the cervical region in man, but that in the dorso-lumbar region it would be possible. He found from dissection that the second and third sacral roots could be joined to the first lumbar root, provided that the latter be divided as low as possible (where it picrees the dura).

Horsley's ${ }^{26}$ views have been so adequately answered by Sriller in his reply to Haynes that I need not further dilate on them.

When are we to recommend operation in cases of fracture-dislocation of the spinal column? In answering this question we must not base our advice on the isolated cases reported in which brilliant results have come after radical operative procedure. These cases are often willo'-the-wisps leading to disaster because we are as yet too ignorant of the processes of regeneration and spinal surgery to be able to see what factor in a particular case made for success, and in our ignorance we are prone to ascribe it to superlative surgical technic, promptness in operating, etc., factors any one of which is easily within our power and which if they were the true crux of the question would forever set aside the dispute on the subject.

A compound fracture of the spinal column, whether caused by gunshot or other violence is often a suitable case for operation. Here there is not the conversion of a simple into a compound fracture. Do as little as possible in the operation in the way of removal or reposi-

22. Organic Nervous Diseases, 1903 , p. 381

23. Injuries to the Spine and Their Treatment, Cincinnati Iancet-Clinic, 1903 , p. 480 .

24. Laminectomy, Jocrial A. M. A., Jan. 6, 1900, vol. xxxiv, p. 12 .

25. An Investigation on the Regeneration of Nerves, with Regard to Surgical Treatment of Certain Paralyses, Brit. Med. Jour., April 27, 1907 , p. 988 .

26. Allbut's System of Medicine, vol. vii, p. 871 . 
tion of fragments. Of course, should one find a lamina driven into the spinal cord, it would be indicated to remove it, but rather than clear the premises of all existing débris, trust to the natural processes of organization and ankylosis, with the aid of immobilization, to bind the fragments, which one might otherwise tediously dissect away, out of reach of the spinal cord. When the canal is opened the greatest care should be exercised in sponging so that the spinal cord is not forcibly pressed on. A great deal of injury can thus be done. I think it better never to let the gauze pad even so much as touch the cord. Clots of blood can be removed by a stream of warm sterile physiologic salt solution, after sufficient time has been given for the oozing in the small vessels to cease spontaneously.

Sculder, ${ }^{27}$ in an attempt to arrive at some conclusion as to the advisability of operating in cases of complete transverse lesion of the cord, does not render the subject more lucid by the following two sentences, which in conflict seem to be past reconciliation: (a) "These specimens . . . demonstrate the utter futility of operative interference in cases of crush of the cord with signs of complete transverse lesion;" and (b) "all fractures showing complete transverse lesion of the cord should be treated by immediate operation."

'There seems to be much testimony in favor of operating in fracture-dislocation involving the cauda equina. Thorburn, ${ }^{12}$ in his classical work, comes to these conclusions: "The operation of trephining the spine for traumatic lesions, as compared with the condition which it is intended to relieve, does not present any great dangers, and appears unlikely to increase the gravity of the prognosis, but that as both a priori argument and the results of published cases show that it is unlikely to be of service, it should be abandoned, except in cases of injury to the cauda equina, and that in the latter, on the other hand, it will probably prove to be an eminently justifiable and serviceable procedure." $\mathrm{He}$ says that if improvement has not started in six weeks in eases of injury of the cauda equina he recommends operation. Scudder, ${ }^{27}$ speaking on the same theme, says, "It" at the end of six weeks evidences of beginning recovery do not appear, or if recovery once begun has ceased, it will be wise to operate on injuries to the cauda equina."

The treatment of the bladder difficulties and trophic disorders must be carried out along the lines of general medicine and surgery. Often in cases of fracture-dislocation of the thoracic region of the spine, the patient will present in due time troublesome meteorismus. This is probably owing to an irritation of the splanchnic inhibitory nerves from the thoracic region of the cord.

\section{DISCUSSION.}

Dr. William G. Spiller, Philadelphia, called attention to the fact that Dr. Allen had failed to give any conclusions. The subject of laminectomy, he said, is one of great importance, and there is much diversity of opinion regarding the value of the operation. After examining many cases of fracture of the vertebræ clinically and pathologically, Dr. Spiller believes that, in most cases, the operation may do harm. There may be exceptions, but in the majority of cases the patient is better treated by other means than surgical. Although this is contrary to the opinion of some surgeons and some neurologists, Dr. Spiller can not help thinking that it is the correct view. He has expressed his opinion more fully in the second volume of "Keen's Surgery."

Dr. Albert E. Sterne, Indianapolis, Ind., did not agree

27. The Treatment of Fracture, 5th ed., 1905. with Dr. Spiller. In certain injuries of the spinal colımn, he said, where the cord is involved in comparatively few instances, it is, in his experience, not the mere fragmentation of the spinal laminx that does the damage. It does damage, but it is not always the chief factor; often, indeed, it is a secondary factor in the damage. The body of the vertebra is pressing against the cord from the front, and the counter-pressure of the lamina at the rear, wedges the cord between these two osseous obstructions. This really does most of the damage. Dr. Sterne thought that by removing the counter-obstruction and the counter-pressure by surgical measures, we are really doing the patient a great deal more good. The operation ought to be done early. Dr. Sterne realizes that there are a few of these cases that do well without operation, but in his experience, and he has seen quite a number of these cases, operation when done early, is the one measure that gives the very best results. If we delay too long, we can not expect results; if secondary degeneration has set in, we can not expect results. If, in the primary injury, the cord is severed partially or worse, we can not expect to obtain results from operation or anything else. We can not determine this; there is no means by which we can know definitely whether the cord is severed or not. He referred to a case of this kind in which an operation was done. A man was shot through the left lung. The natural assumption was that the bullet had passed through the lung to the right of the spinal column. Dr. Sterne could not feel it with his finger, and he feared that the cord was severed. Three weeks after the shooting the man was absolutely paralyzed, without deep reflexes, with blood in the urine, with all of the symptoms naturally resulting from perforation of the lung, and with extensive bed sores from the point of the injury downward. Dr. Sterne operated, and on removing the bullet, he found the cord absolutely uninjured. The bullet had passed over the spinal cord and was lying against the lateral process almost in the canal, compressing the cord, but without any reflexes from this pressure. After the removal of the bullet the patient made an uninterrupted recovery, in spite of the fact that he had a perforation of the lung. Dr. Sterne knows of no method by which we can say absolutely whether the cord is severed or not, and in lieu of this fact it seems to him that we fail to give the patient every benefit of the doubt unless we determine this by operation. Furthermore, it makes little difference as to the nature of the object causing pressure on the cord-whether foreign body, bone or a blood clot of magnitude.

Dr. Alfred Reginald Allen, Philadelphia, asked whether there was any evidence that the dura had been touched, and was the motor power in that case restored. Dr. Sterne replied that the bullet had passed over the cord, but did not lacerate the dura. It was, however, pressed against the dura and cord by the overlying bone. There was practically no blood-clot within the canal, either above or below the level of injury. Motor power was almost completely restored at the time the patient left his observation and he understands that the man is at present actively at work.

Dr. Wm. A. Jones, Minneapolis, Minn., believes that patients do better without operation, and he is in perfect accord with what Dr. Spiller said. He has seen patients operated on make good recoveries, and he has seen a number of patients that were not operated on that made practical recoveries; that is, they so far recovered that they were able to perform a number of their duties. In the case of irritation reported by Dr. Sterne in which the bullet did not puncture the spinal cord, Dr. Jones thought that the patient would probably have gotten just as well without operation as by extirpation of the bullet. He believes that too much laminectomy and spinal surgery is being done with more harm than good, except in very rare cases.

Dr. H. M. Thomas, Baltimore, has never been convinced that the operation in cases of this character has been of the least benefit. Perhaps, he said, his eases have been unfortunate ones. The cord symptoms in these cases he believes to be due either to complete destruction by the fracture dislocation, and to be practically irreparable, or to hemorrhage into the cord, which is a condition that has a tendency to improve markedly. 
In the cases whore the dislocated bones actually compress the cord, it is obvious that an operation is indicated, but apparently these cases are not very common. Dr. Thomas cited the case of a boy who came to the surgical dispensary of the Johns Hopkins Hospital, complaining simply of a stiff neck. He was perfeetly well in other respects; had absolutely no paralyses or other nervous symptoms. On examination it was found that one of the spines of the cervical vertebræ seemed to be dejressed and an $x$-ray examination revealed a condition that was taken to demonstrate a dislocation forward of the fourth cervical vertebra. The boy was so little incommoded that he did not return to the hospital and has been lost sight of.

Dr. Cuarles K. Mills, Philadelphia, said that his experience, in a general way, is against operation for fractures of the spine; but he did not agree with Dr. Spiller that operation should never be performed in these cases. He has seen a very few instances in which it has been of value. One mistake, which is sometimes made, is in doing the operation too soon after the injury. Operation should be done neither too eariy nor too late. It should be performed, if at all, within a reasonable period after, but not too far removed from the accident. High operations nearly always prove disastrous; that is, operations on the cervical and upper thoracic vertebræ. Dr. Mills has seen patients who were not operated on and who seemed to be extremely serious if not absolutely hopeless cases, but they made an approximate recovery after a long time.

Dr. Philip ZenNer, Cincinnati, Ohio, has seen two cases within the last six or eight months that would lead one to hesitate as to operating. One patient, aged 18 or 20 years, in doing some stunts on his bedstead, fell on his head and fractured the fourth or fifth cervical vertebra, as shown by the $x$-ray picture. Examination showed that he had paralysis of both arms, bladder and rectum, and was suffering from extreme pain. Three or four months later all of the symptoms had disappeared. A second patient had been injured very seriously some four months previously in the sacral and lower lumbar region. He had been completely paralyzed, according to his statement, and for a month he could not move his legs at all. When Dr. Zenner saw him one leg was normal, while in the other there was anesthesia and paralysis of some of the muscles of the foot. Such cases, he thought, show that we may be fortunate if we hesitate to operate.

Dr. C. C. Hersmann, Pittsburg, also agreed with Dr. Spiller. However, he can remember when the same was said with regard to trephining. When he was a medical student, the professor advised never to trephine as a rule, but to trephine as an exception. Dr. Sterne, he thought, was either utterly mistaken, or his knowledge was at fault. Among the many cases of spinal injuries which Dr. Hersmann has seen in the last twenty years or more there has been only one patient that apparently recovered. The boy fell out of an apple tree, and "broke his neck." Laminectomy was done, and the boy apparently made a good recovery. However, Dr. Hersmann has seen very few cases of spinal injury benefited after operation, and he believes as many patients would recover without operative interference, as with it.

Dr. Monton Prince, Boston, Mass., has gone over the records of the Boston City Hopital cases of spinal cord injuries for some twenty years back, and has been attempting for some time to follow up aı the cases after leaving the hospital, with a view to learning what the final result has been. Taking the cases that have occurred during a long period of time, and after having observed personally a large number of cases operated and not operated on, Dr. Prince has seen improvement without operation and improvement following operation, but he can not say that he has ever seen any improvement which he could logically and certainly attribute to the operation itself. Operations for traumatism of the cord are nowadays rarely recommended either by his neurological colleagues or by himself, unless there is some exceptional reason to justify this course. And yet the prognosis in severe cases, when there is reason to believe the lesion of the cord is complete, is so hopelessly bad, that he has felt that there is no particular objection to any surgeon trying the operation if he wishes to do so. Dr. Prince would not go as far as Dr. Spiller does in saying that it actually does harm, although the operation, in his opinion, is not nearly as harmless as it is sometimes said to be, but is attended by considerable danger, meaning immediate risk to life, particularly in the hands of surgeons who are not skilled in the technic.

Dr. Sterne asked whether that also included the operations of choice for other injuries on the cord.

Dr. Prince replied that he was speaking of fractures and dislocations causing structural injuries to the cord such as frequently come into the hospital.

Dr. SPILLER remarked that he did not say that no case of fracture should be operated on, nor that operation is necessarily injurious, but that it may be injurious. In one case the evil effects of operation were clearly shown.

Dr. Alfred Regivald Allen, Philadelphia, answering Dr. Sterne, said that, in the first place, there is no saying definitely that the cord is destroyed or that it is not. Even weeks or months will not answer that question in some cases. In others there is an absolute abolition of all the reflexes, and absolute abolition of all sensory and motor phenomena, from which one would be led to suppose that there is a complete lesion of the cord, and yet in the course of time the patient gets well, even without operation. There are a number of such cases on record. In a case referred to in the paper there was no point of exit of the bullet. The man was paralrzed, and Dr. Spiller diagnosed the level of the lesion. When the case came to autopsy the bullet was found imbedded in that particular vertebra. In passing it had not wounded the dura in the least, but had evidently just touched it. The cord for a distance of about $4 \mathrm{~cm}$. was completely destroyed. Dr. Allen thought that in Dr. Sterne's case, instead of com. rletely destroying the cord, the bullet did what frequently happens in fracture dislocations-it produced enough temporary injury to cause the paralysis and the other symptoms. Even some of the severest cases get well without operation. Like Dr. Spiller, he holds that these cases are better left alone surgically. In fact, judging from the hundreds of cases" that he has gone over in the last eight months, he does not believe that we are justified in operating, except in a very few instances, until by experimental surgery on the lower animals we get some method of suturing the spinal cord. Dr. Thomas' case, he thought, was one in which, from his description of cervical dislocation, the upper or luxated vertebra had slipped forward, the inferior articular process locking in front of the superior articular process of the vertebra next below.

\section{THE EPIDEMIC OCCURRENCE OF CANCER IN FISHERSVILLE, VA., AND VICINITY.*}

A. L. TYNES, M.D.

Secretary of Augusta County Medical Society. FISIIERSVILLE, va.

The principal facts of the histogenesis and structural peculiarities arising from different types of tissues have been pretty well worked out ${ }^{1}$ and the workers in this field have allied themselves with the bacteriologist, chemist and biologist in their efiorts to determine the etiology of malignant tumors, but so far they are unable even to. determine whether cancer is of internal or external origin. There is much evidence in support of the theory that cancer is due to some micro-organism, and certain protozoa have been accredited with being the cause, but skepticism still prevails among the rank and file of the profession.

The experimental investigation of cancer in animals is, perhaps, the most recent and most promising field of research and the studies of Gaylord and Clows, and of Leo Loeb, in this country, have done much to stimulate interest along biologic lines. There is much yet to be

* Read before the Medical Society of Virginia, Nov. 13, 1907

1. Observations on the Inoculability of Tumors, etc., Interna1. Observations on the Inoculability
tional Clinics, vol. iii, Seventeenth series. 